\title{
The role of the pharmacist from development to pharmacovigilance of biosimilars
}

\author{
İmge KUNTER 1, *, Halimat Olusola BALOGUN ${ }^{1}$, Gönül ŞAHİN ${ }^{1}$ \\ 1 Faculty of Pharmacy, Eastern Mediterranean University, Gazimagusa, Turkish Republic of Northern Cyprus via \\ Mersin 10 Turkey, 99628 \\ * $\quad$ Correspondence: imge.kunter@emu.edu.tr (İ.K.); Tel: +90 39263028 68; Fax: +90 39263028 19; ORCID No: 0000- \\ 0001-5706-306X.
}

Received: 12 January 2018; Revised: 11 March 2018; Accepted: 19 March 2018

\begin{abstract}
Biologics such as vaccines, recombinant proteins and antibodies are used to treat or prevent different chronic and complex diseases and they have a high market share. Improvements in biotechnology, leads increased production and use of these products. Because of high manufacturing cost, they are expensive and have significant drawbacks about their use and patient accessibility. Biosimilars are cost-effective therapeutic alternatives of biologics, which can be marketed after the expiry of the patent of the reference biologic. Biosimilars can provide cheaper alternatives and they can help reduce health care expenditure significantly. Although there are many publications related to the importance of biosimilars in the literature, there are not enough studies on the role of the pharmacist from development to pharmacovigilance of these drugs. In this article, besides the importance of these drugs we addressed the crucial contribution of the pharmacists in preparation of biosimilar drugs, establishing regulations and approval pathways to take place in the market and the investigation of the side effects after marketing. We also emphasized the role of pharmacist at development, manufacturing, dispensing, post-marketing pharmacovigilance, regulations and usage of biosimilars.
\end{abstract}

KEYWORDS: Biologics; bio-pharmaceutics; biosimilars; role of pharmacist.

\section{INTRODUCTION}

As a result of rapid changes in health care delivery, the pharmacy profession has been experiencing significant growth and development and nowadays biotechnology and genetic engineered medicines called "biologics" have started to be used in the treatment of diseases by physicians and pharmacist [1].

The advent of recombinant biotechnology brought a new dawn to management and treatment of chronic diseases including rheumatoid arthritis, inflammatory bowel diseases, psoriasis, renal anemia, lymphoma, cancer, diabetes, and other diseases [2-3].

Biologics are also being referred to as bio-pharmaceutics [2-4]. The use of biotechnology derived biologics in treatment and management of disease can be dated back to the use of vaccines for immunization and to 1982 when recombinant human insulin was first produced for the treatment of diabetes [5]. In the last decade, our understanding about complex diseases has increased under the light of developing science. These new information increases emerged deficiencies associated with existing therapies. Besides increasing knowledge of molecular and cellular biology techniques, such as genomics and proteomics, microarray, cell culture, and monoclonal antibody technologies lead to develop potential new biologic drugs.

Subsequently, global commercial development of biologic therapeutics and use of biologics for treatment of many other chronic and complex diseases such as auto-immune disorders, inflammatory disorders and neoplasms, growth deficiency and diabetes has dramatically increased [6-8]. This is evident by the increase in prescription and sales of biologics. In 2008, five out of ten drug sales were of biologics. Global sales of 167 billion US dollar was estimated for 2015 and it was estimated for 2016 that with a global spending of 200-210 billion US dollars, ten of the twenty top-selling drugs globally would be biologics [9-11].

How to cite this article: Kunter I, Balogun HO, Şahin G. The role of the pharmacist from development to pharmacovigilance of biosimilars. Marmara Pharm J. 2018; 22 (4): 469-473. 


\section{BIOLOGICS VERSUS SMALL MOLECULAR DRUGS}

Small molecular drugs are therapeutic molecules typically manufactured through standard chemical synthesis which have well-defined, noncomplex chemical structures with low molecular weight. But biologics are therapeutic substances having complex structure, extracted from living organisms or, manufactured by way of biotechnology using living cells or organisms as their substrate [4, 12]. By contrast to small molecular drugs, it is difficult to characterize their structure [7]. Biologic drugs, vaccines, gene therapy, recombinant proteins, antibodies, have been able to increase the rate of treatment of these diseases and improve quality of life of patient [8].

The advent of biologics, especially recombinant products, has brought great development to the health sector and medical research area but the consequential increase in health care expenditure has been a huge drawback on the use of biologics and patient accessibility. Because of these reasons scientists should be supported especially in the area of biosimilar production by government and authorities because arriving new biosimilar drugs could decrease overall cost of health expenditure.

A similar situation was available for innovative small molecule drugs used for longer time than biologics and introduction of generic of small molecule drugs proved a good measure to cut down on health care expenditure. After patent expiration of innovative small molecule drugs, generic companies are allowed to produce and market their product at about $80 \%$ less price than the reference product. This situation ensures that generic drugs can reach more people with lower costs $[11,13]$.

\section{GENERICS VERSUS BIOSIMILARS}

Generics are non-innovative small molecule drugs that are scientifically proven by chemical characterization, quality, performance characteristics, intended use, and bioequivalence to be the same as the innovative molecule. Producing generic of small molecule drugs is quite easy because it is expected that products of the same chemical group and pharmacophore will give the same effect and bioavailability in the body. There is usually extrapolation of data from the innovative molecule so the generic company does not need to carry out clinical and non-clinical trials. Less is spent in production of small molecule generic and these accounts for the price reduction in sales of generic drugs [14-15].

As generic drugs, non-innovative versions of biologics (biosimilars) can be marketed after expiry of the patent of the reference biologic product. Success in the use of generic drugs to cut down health care expenditure is a promising hope that the price of biologics can also be cut down with biosimilars and more biologic drugs can be made accessible and/or affordable to patients. Because of these reasons, biosimilar market is expected to increase significantly in the next decade [15-16]. However, the complexity of biologic molecule is the stumbling block which, has to be considered before approving biosimilars by authorities [17].

\section{WHAT ARE BIOSIMILARS?}

Biosimilars are non-innovative copy versions of biologics which are scientifically proven to be clinically equivalent to, as efficacious and safe as the reference biologics, not considering the small difference in nonclinical components and are approved through abbreviated pathway [18-19]. Biosimilars are cost-effective therapeutic alternatives to their reference biologic products in terms of their safety, quality and efficacy.

Biosimilars are quite different from small molecule generics in terms of the complexity in their structure, characterization, molecular size, production process involving living organisms or cells, mechanism of action and immunogenicity [20]. Unlike small molecule generics which have distinct chemical characterizations which make it possible to accurately predict their therapeutic activity, biologics are basically protein molecules that are significantly affected by a slight change in manufacturing process and storage conditions [17, 21]. They are basically produced from distinct DNA regions and cell lines by distinct manufacturing processes, which are propriety to the innovative company. Thus, generic of biologics are referred to as biosimilars because, slight clinically insignificant differences are expected to exist and do exist between reference biologics and their similars [22]. Due to these reasons, different polices from those of small molecule generics apply to biosimilars. These include different approval pathways and guidelines, controversial nomenclature system, duration and expiration of patency, data exclusivity period, substitution and interchangeability [23]. 


\section{ROLES OF THE PHARMACIST}

Pharmacist is the expert in all drugs and is also the most appropriate source of information about the use, therapeutic effect, adverse effect, mode of action, mode of administration, storage and dispensing of all drugs including biologics and biosimilars [24]. All drugs and drug products produced by conventional chemical synthesis or by ways of biotechnology or any other means remains the responsibility of the pharmacist [2526]. The role of the pharmacist in the development of biosimilars is continuous starting from manufacturing to dispensing and post-marketing pharmacovigilance studies. Pharmacists must be well informed about new regulations and policies about biosimilars. As they have close contact with patients, they should also be involved in the policy making and regulation processes. Besides education and counseling of stakeholders about the designing process, regulations and use of biosimilars are also among the responsibilities of the pharmacist [25-27].

\subsection{The roles of the pharmacist in development, designing and dispensing of finished dosage forms}

Biologics and biosimilars have been greatly attributed to science of biotechnology. This is due to the processes involved in their manufacturing as the use of living cells and artificial biological environments such as bioreactors and culture systems [7, 12]. Pharmacists are experts who have scientific background information about pathological mechanisms of diseases, mechanisms of action of biologicals and biotechnology tools used for designing biosimilars. Pharmacists are at forefront in designing appropriate dosage forms and devices for all drug formulations to ensure safety, efficacy and easy administration. The view of the pharmacist is very important in designing a suitable dosage form and packing. Dosage form of the dispensed biosimilar is important, relevant counseling should be provided to the patient by the dispensing pharmacist, ensuring that the directions are well understood by the patients and can appropriately be administered by the patient/career [28].

\subsection{The roles of the pharmacist in policy making and regulation}

Pharmacists should be included in policy making and regulation regarding biosimilars. Till this date, there are issues yet to be decided about biosimilars due to the complexity of the product structure and other parameters related with the product. There are ongoing debates about naming system to adopt for biosimilars, the right of interchangeability, substitution and extrapolation of indications. While the innovative company may be fighting to maintain their market share and avoid competition, biosimilar advocates may be more interested in tapping from the fast growing biologic market. Pharmacists are in a position to maintain the balance between the two groups by observing this debate from the patients' perspective to provide quality products readily accessible and at affordable prices [22, 24-26].

\subsection{The roles of the pharmacist in education and counseling}

Pharmacists form the bridge between companies and doctors and also between doctors and patients. Pharmacists stand as educators to other pharmacists, the physicians, payers, health care professionals and patients. Pharmacist must continuously keep themselves updated on all new policies, regulations and new biosimilar products in the market. It is expected that some physicians and patients will display a level of resistance to accept new drugs due to uncertainty and inadequate information. It is the responsibility of the pharmacist both at the community level and in the health care institute to inform all stakeholders involved in the use of biosimilars [29]. Educating the patients and counseling is one of the main responsibilities of the pharmacist. Assuring physicians and patients on the level of similarity, safety and efficacy of a biosimilar relative to the reference product is paramount before price reduction. This is because the health and safety of the patient is always the top priority.

Biosimilars will be able to attain a good market share and potential price reduction only when pharmacists are able to educate and convince the physician and patients to accept biosimilars [29-30]. 


\subsection{The roles of the pharmacist in pharmacovigilance and post-marketing monitoring}

Post-marketing monitoring of biosimilar products or pharmacovigilance is a requirement in all biosimilar guidelines due to limited clinical trials. Pharmacists are at a pivotal position to enable collection of pharmacovigilance data and post-marketing monitoring in many countries [27-30]. Adequate involvement of pharmacists is important to ensure that all identification information about the dispensed biosimilar such as the name of the product, batch number, manufacturing company, indication, etc. are retained in the pharmacy. Presenting signs of adverse reactions are also recorded for follow-up studies on the post-approval products.

Author contributions: Concept - İ.K., H.O.B. G.Ş.; Design - İ.K., H.O.B.; Supervision - I.K, G.Ş; Resource - İ.K., H.O.B; Analysis and/or Interpretation - I.K, G.Ş.; Literature Search - İ.K., H.O.B.; Writing - İ.K., H.O.B; Critical Reviews İ.K., H.O.B., G.Ş.

Conflict of interest statement: The authors received no financial support for the research, authorship, and/or publication of this article. The authors declare no conflict of interest.

\section{REFERENCES}

[1] Dolinar R, Reilly M. The future of biological therapy : a pathway forward for biosimilars. GaBI J. 2013; 2(1): 36-40.

[2] Crommelin DJA, Storm G, Verrijk R, Leedeb L, Jiskoot W, Hennink WE. Shifting paradigms: Biopharmaceuticals versus low molecular weight drugs. Int J Pharm. 2003; 266(1-2): 3-16.

[3] Rader RA. (Re)defining biopharmaceutical. Nat Biotechnol. 2008; 26(7): 743-751.

[4] Sekhon BS. Biopharmaceuticals: an overview Bhupinder. Thai J Pharm Sci. 2010; 34: 1-19.

[5] Heinemann L, Khatami H, McKinnon R, Home P. An overview of current regulatory requirements for approval of biosimilar insulins. Diabetes Technol Ther. 2015; 17(7): 1-17.

[6] Dempke WCM, Fenchel K, Uciechowski P, Dale SP. Second- and third-generation drugs for immuno-oncology treatment-The more the better? Eur J Cancer. 2017; 74: 55-72.

[7] Morrow T, Felcone LH. Defining the difference: What makes biologics unique. Biotechnol Healthc. 2004; 1(4): 24-9.

[8] Emmanouilides CE, Karampola MI, Beredima M. Biosimilars: Hope and concern. J Oncol Pharm Pract. 2015; 22(4): 618-624.

[9] U.S Food and Drug Administration Global Engagement - U.S. Food and Drug Administration. Off Int ProgramsFDA 2011; 1-44. https://www.fda.gov/downloads/AboutFDA/ReportsManualsForms/Reports/UCM298578.pdf (accessed May 22, 2017).

[10] Aitken M. The Global Use of Medicines : Outlook Through 2015. 2011; 1-42.

[11] Aitken M, Kleinrock M, Lyle J, Nass D, Caskey L. Global Outlook for Medicines Through 2018. IMS Inst. Healthc. Informatics 2014. http:// static.correofarmaceutico.com/docs/2014/12/01/informe_ims.pdf (accessed december $22,2017)$.

[12] Jozala AF, Geraldes DC, Tundisi LL, Feitosa VA, Breyer CA, Cardoso SL, Mazzola PG, Oliveira NL, Rangel YCO, Magalhães PO, Oliveira MA, Pessoa A Jr. Biopharmaceuticals from microorganisms: from production to purification. Braz J Microbiol. 2016; 47: 51-63.

[13] Davit B, Braddy AC, Conner DP, Yu LX. International guidelines for bioequivalence of systemically available orally administered generic drug products: a survey of similarities and differences. AAPS J. 2013; 15(4): 974-990.

[14] Dunne S, Shannon B, Dunne C, Cullen W. A review of the differences and similarities between generic drugs and their originator counterparts, including economic benefits associated with usage of generic medicines, using Ireland as a case study. BMC Pharmacol Toxicol. 2013; 14: 1-19.

[15] Gothe H, Schall I, Saverno K, Mitrovic M, Luzak A, Brixner D, Siebert U. The impact of generic substitution on health and economic outcomes: A systematic review. Appl Health Econ Health Policy. 2015; 13(S2): 1-33.

[16] ITA 2016 Top Markets Report Pharmaceuticals Overview and Key Findings. 2016; 1-10. https://www.trade.gov/topmarkets/pdf/Pharmaceuticals_Executive_Summary.pdf (accessed Ocotber 2017). 
[17] Declerck P, Danesi R, Petersel D, Jacobs I. The language of biosimilars: Clarification, definitions, and regulatory aspects. Drugs. 2017; 77(6): 671-677.

[18] Wang J, Chow SC. On the regulatory approval pathway of biosimilar products. Pharmaceuticals. 2012; 5(4): 353-368.

[19] McCamish M, Gallagher AM, Orloff J. Biosimilar by name and biosimilar by nature. RPM Rep 2013. https://www.sandoz.com/sites/www.sandoz.com/files/rpm-report.pdf (accessed december 22, 2017).

[20] Grampp G, Ramanan S. The diversity of biosimilar design and development: Implications for policies and stakeholders. BioDrugs. 2015; 29(6): 365-372.

[21] Declerck P, Farouk-Rezk M, Rudd PM. Biosimilarity versus manufacturing change: Two distinct concepts. Pharm Res. 2016; 33(2): 261-268.

[22] Ventola CL. Evaluation of biosimilars for formulary inclusion: Factors for consideration by P\&T committees. P T. 2015; 40(10): 680-689.

[23] Committee for Medicinal Products for Human Use (EMA) Guideline on similar biological medicinal products. 2014; 44, 1-7.

[24] Smith M, Bates DW, Bodenheimer TS. Pharmacists belong in accountable care organizations and integrated care teams. Health Aff. 2013; 32(11): 1963-1970.

[25] Li E, Ramanan S, Green L. Pharmacist substitution of biological products: Issues and considerations. J Manag Care Spec Pharm. 2015; 21(7): 532-539.

[26] Strand MA, Scott DM, Undem T, Anderson G, Clarens A, Liu X. Pharmacist contributions to the ten essential services of public health in three National Association of Boards of Pharmacy regions. J Am Pharm Assoc. 2017; 57(3): 395401.

[27] Saseen JJ, Ripley TL, Bondi D, Burke JM, Cohen LJ, McBane S, McConnell KJ, Sackey B, Sanoski C, Simonyan A, Taylor J, Vande Griend JP. ACCP clinical pharmacist competencies. Pharmacother J Hum Pharmacol Drug Ther. 2017; 37(5): 630-636.

[28] Griffith N, McBride A, Stevenson JG, Green L. formulary selection criteria for biosimilars: Considerations for US health-system pharmacists. Hosp Pharm. 2014; 49: 813-825.

[29] Jarrett S, Dingermann T. Biosimilars are here: A hospital pharmacist's guide to educating health care professionals on biosimilars. Hosp Pharm. 2015; 50(10): 884-893.

[30] Lucio SD. Biosimilars: Primer for the health-system pharmacist. Am J Health-Syst Pharm. 2014; 70(22): $2004-2017$.

This is an open access article which is publicly available on our journal's website under Institutional Repository at http://dspace.marmara.edu.tr. 